\title{
Tubal pregnancy with embryo
}

\section{Ed Uthman*}

\begin{abstract}
This photo of an opened oviduct with an ectopic pregnancy features a spectacularly well preserved 10-millimeter embryo. It is uncommon to see any embryo at all in an ectopic, and for one to be this well preserved (and undisturbed by the prosector's knife) is quite unusual.

Even an embryo this tiny shows very distinct anatomic features, including tail, limb buds, heart (which actually protrudes from the chest), eye cups, cornea/lens, brain, and prominent segmentation into somites. The gestational sac is surrounded by myriad chorionic villi resembling elongated party balloons. The age of this embryo is 7 weeks of gestational age.
\end{abstract}

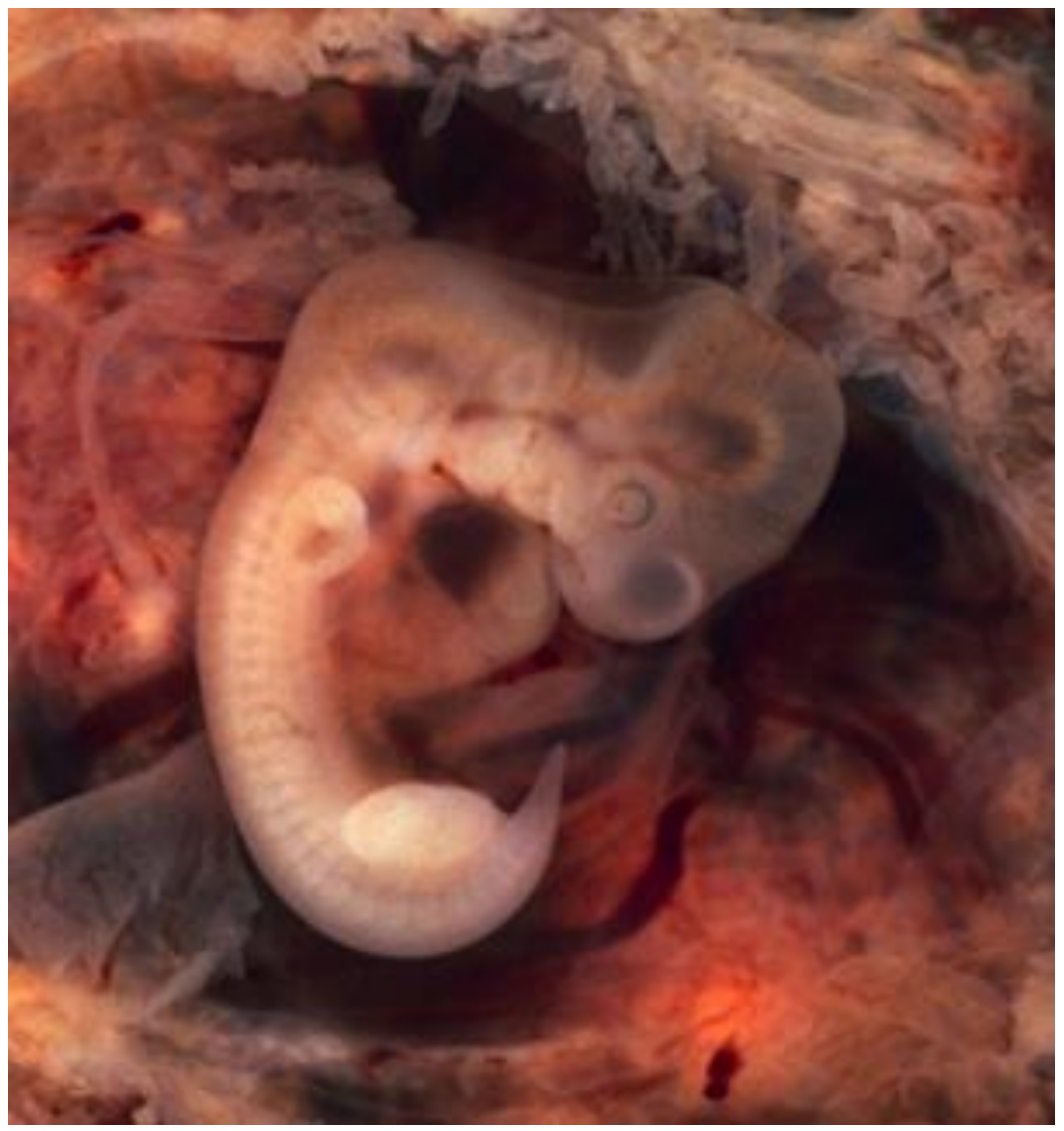

The photo was taken on Kodak Elite 200 slide film, with a Minolta X-370 camera and $100 \mathrm{~mm}$ f/4 Rokkor bellows lens at near-full extension. The formalin-fixed specimen was immersed in tap-water and pinned to a tray lined with black velvet. The exposure was $1 / 4$ second at $\mathrm{f} / 8$.

\section{Acknowledgements}

Conflict of Interest: none declared.

Figure 1 | Human embryo (7th week of pregnancy, 5th week p.o.)

\footnotetext{
*Author correspondence: by online form 